\title{
Characteristics of the Life History of Grey Mullet from Taiwanese Waters
}

\author{
Wei Cheng Su*1 and Tsuyoshi Kawasaki*2 \\ ${ }^{* 1}$ Kaohsiung Branch, Taiwan Fisheries Research Institute, Kaohsiung, Taiwan 806, ROC \\ ${ }^{*}$ Kugenuma-Fujigaya 1-10-6, Fujisawa, Kanagawa 251, Japan
}

(Received December 27, 1993)

\begin{abstract}
One population of the grey mullet mugil cephalus inhabits the waters around the Taiwan Strait and in the spawning season migrates to the coasts of southern Taiwan. The grey mullet is long-lived and produces a great number of small, nonbuoyant eggs. The female grows larger in size and shows high GSIs than the male. Lee's phenomenon is marked in the grey mullet. These characteristics of grey mullet correspond well to its relatively stable pattern of fluctuation in numbers. None of the fish species examined by one of the authors, Kawasaki, shows such characteristics, which is interesting from the viewpoint of evolutionary ecology.
\end{abstract}

Key words: grey mullet, life history, growth pattern, gonadosomatic index, fecundity

The life history of the grey mullet Mugil cephalus inhabiting the Taiwan Strait, waters between mainland China and Taiwan, is interesting from the viewpoint of evolutionary ecology. Grey mullet are usually distributed along the coasts of southern mainland China, but between late November and late the following January, they migrate to the western coasts of Taiwan for spawning. Although a number of papers ${ }^{1-6)}$ on the biology of grey mullet in this area have been published, the adaptive and ecological significance of their life histories has never been described to date.

In the present paper, the growth and reproductive strategy of the grey mullet, which indicate their life histories (Kawasaki ${ }^{7,8)}$ and Kawasaki et al. ${ }^{97}$ ) and hence determine the fluctuation pattern in numbers, are examined.

\section{Materials and Methods}

Tung1) noted that the annual ring on a mullet's scale in the waters around Taiwan is formed from January to February.

Scales were collected from 137 fernales and 198 males caught by purse seiners during 1985-87. Scales taken from the central portion of the body just posterior to the pectoral fin were used for ageing. Body length was measured and scales were taken during 1976-84 for 500-1000 fish annually. All the specimens were collected at fish markets at Hsinchu, Chiehting, etc., located on the western coasts of Taiwan during the spawning season from late November to late January.

Ninety five specimens caught by purse seiners, gill netters, and set nets were also collected from the fish markets at Hainchu, Chiehting, etc., during the spawning season in 1985-87 in order to study reproduction. Gonads were weighed and oocyte diameter was measured to obtain frequency distributions. The number of ovulating eggs was estimated by the gravimetric method. The number of developing oocytes in an ovary was also estimated by the same method. Since the size distributions of the developing oocytes from different portions of an ovary were almost similar, samples were taken from the central part of the ovary to estimate the total number of developing oocytes in the ovary.

\section{Results}

\section{Growth}

The relationship between the scale radius in $\mathrm{mm}(\mathrm{R})$ and the body length in mm (BL) of grey mullet is expressed by linear regression equations:

Female: $\mathrm{BL}=22.4 \mathrm{R}+186.2(\mathrm{r}=0.71)$

Male: $B L=28.2 R+176.5(r=0.65)$

From an analysis of covariance, ${ }^{10}$ no significant difference was found between the regression coefficients of the two sexes, and a common equation was obtained:

$$
\mathrm{BL}=27.3 \mathrm{R}+160.8(\mathrm{r}=0.71)
$$

Mean ring radii at the time of ring formation for each ring group and those for all ring groups combined were calcuated for each sex (Table 1). Average body lengths at ring formation are also shown in Table 1 . We can clearly see Lee's phenomenon for both sexes, and the phenomenon is more noticeable for the female than for the male.

Because the correlation coefficient between body length and scale radius is not so high, we used the observed length rather than the length calculated from the scales for this growth study. The mean observed length of both sexes shown in Table 2 was obtained from average annual length measured during 1976 to 1984.

Walford's growth transformation from mean observed length was carried out for both sexes as shown below:

Female: $L_{n+1}=0.814 L_{n}+104.09(r=0.997)$

Male: $\mathrm{L}_{\mathrm{n}+1}=0.797 \mathrm{~L}_{\mathrm{n}}+108.54(\mathrm{r}=0.992)$

where $L_{n}$ and $L_{n+1}$ are length in $m m$ at age $n$ and $n+1$, respectively (Figs. $1 \mathrm{~A}$ and $2 \mathrm{~A}$ ).

In Figs. $1 \mathrm{~A}$ and $2 \mathrm{~A}$, minus ages are seen, which shows that younger mullet follow growth patterns different from those for older fish. Growth curves were drawn freehand from the observed lengths and the lengths of one-year-old female and male grey mullet were obtained as $247 \mathrm{~mm}$ and $233 \mathrm{~mm}$, respectively (Figs. 1B and 2B). Walford's growth 
Table 1. Mean ring-radii ( $\mathrm{r}: \mathrm{mm})$ and body length (l: $\mathrm{mm})$ at time of ring-formation with standard deviation (lower) (Female)

\begin{tabular}{|c|c|c|c|c|c|c|}
\hline $\begin{array}{l}\text { Ring } \\
\text { group }\end{array}$ & $\begin{array}{l}\text { No. of } \\
\text { fish }\end{array}$ & $r_{1}$ & $r_{2}$ & $r_{3}$ & $r_{4}$ & $r_{5}$ \\
\hline \multirow{2}{*}{ II } & \multirow{2}{*}{15} & 4.434 & 7.042 & & & \\
\hline & & 0.457 & 0.466 & & & \\
\hline \multirow{2}{*}{ III } & \multirow{2}{*}{69} & 3.980 & 6.545 & 8.317 & & \\
\hline & & 0.531 & 0.634 & 0.648 & & \\
\hline \multirow{2}{*}{ IV } & \multirow{2}{*}{41} & 3.748 & 6.183 & 7.910 & 9.163 & \\
\hline & & 0.407 & 0.555 & 0.599 & 0.656 & \\
\hline \multirow{2}{*}{ V } & \multirow{2}{*}{12} & 3.767 & 5.953 & 7.615 & 8.765 & 9.778 \\
\hline & & 0.423 & 0.503 & 0.426 & 0.453 & 0.431 \\
\hline \multirow{4}{*}{$\begin{array}{l}\text { All ring } \\
\text { groups } \\
\text { combined }\end{array}$} & \multirow[b]{2}{*}{$\mathbf{r}_{\mathrm{i}}$} & 3.982 & 6.431 & 7.947 & 8.964 & 9.778 \\
\hline & & 0.429 & 0.521 & 0.616 & 0.610 & 0.431 \\
\hline & \multirow{2}{*}{$l_{1}$} & 269.5 & 336.4 & 377.8 & 405.5 & 427.8 \\
\hline & & 13.16 & 17.64 & 21.43 & 21.97 & 11.73 \\
\hline \multicolumn{7}{|l|}{ (Male) } \\
\hline $\begin{array}{l}\text { Ring } \\
\text { group }\end{array}$ & $\begin{array}{l}\text { No. of } \\
\text { fish }\end{array}$ & $\mathbf{r}_{1}$ & $\mathbf{r}_{2}$ & $\mathbf{r}_{3}$ & $\mathbf{r}_{4}$ & $r_{5}$ \\
\hline \multirow{2}{*}{ II } & \multirow{2}{*}{33} & 4.090 & 6.596 & & & \\
\hline & & 0.567 & 0.704 & & & \\
\hline \multirow{2}{*}{ III } & \multirow{2}{*}{113} & 3.925 & 6.427 & 8.066 & & \\
\hline & & 0.502 & 0.710 & 0.718 & & \\
\hline \multirow{2}{*}{ IV } & \multirow{2}{*}{45} & 3.752 & 5.948 & 7.512 & 8.456 & \\
\hline & & 0.450 & 0.650 & 0.740 & 1.440 & \\
\hline \multirow{2}{*}{ V } & \multirow{2}{*}{7} & 3.794 & 5.863 & 7.404 & 8.543 & 9.286 \\
\hline & & 0.261 & 0.649 & 0.484 & 0.544 & 0.596 \\
\hline \multirow{4}{*}{$\begin{array}{l}\text { All ring } \\
\text { groups } \\
\text { combined }\end{array}$} & \multirow[t]{2}{*}{$r_{i}$} & 3.890 & 6.209 & 7.661 & 8.500 & 9.286 \\
\hline & & 0.493 & 0.694 & 0.714 & 1.319 & 0.569 \\
\hline & \multirow[b]{2}{*}{$l_{i}$} & 267.0 & 330.3 & 370.0 & 392.9 & 414.3 \\
\hline & & 15.95 & 23.12 & 24.68 & 25.63 & 16.31 \\
\hline
\end{tabular}

Table 2. Walford's growth transformation from mean observed lengths $(\mathrm{mm})$ by both sexes

\begin{tabular}{|c|c|c|c|c|c|c|}
\hline \multirow{3}{*}{ Age } & \multicolumn{4}{|c|}{ von Bertalanffy's transformation } & \multirow{2}{*}{\multicolumn{2}{|c|}{$\begin{array}{c}\text { Mean observed } \\
\text { length }\end{array}$}} \\
\hline & \multicolumn{2}{|c|}{ Length } & \multicolumn{2}{|c|}{ Annual increase } & & \\
\hline & Female & Male & Female & Male & Female & Male \\
\hline 1 & 247.0 & 234.1 & 247.0 & 234.1 & & \\
\hline 2 & 348.0 & 333.0 & 101.0 & 98.9 & 348 & 333 \\
\hline 3 & 386.0 & 374.5 & 38.0 & 41.5 & 388 & 376 \\
\hline 4 & 418.8 & 407,1 & 32.8 & 32.6 & 417 & 403 \\
\hline 5 & 445.1 & 433.0 & 26.3 & 25.9 & 446 & 434 \\
\hline 6 & 466.5 & 453.8 & 21.4 & 20.8 & 469 & 449 \\
\hline 7 & 483.9 & 470.3 & 17.6 & 16.5 & 481 & 474 \\
\hline 8 & 498.0 & 483.4 & 14.1 & 13.1 & 498 & 484 \\
\hline 9 & 509.6 & 493.9 & 11.6 & 10.5 & & \\
\hline 10 & 519.0 & 502.2 & 9.4 & 8.3 & & \\
\hline 11 & 526.6 & 508.9 & 7.6 & 6.7 & & \\
\hline 12 & 532.8 & 514.2 & 6.2 & 5.3 & & \\
\hline
\end{tabular}

transformation of younger mullet was made from the observed length of 2-year-old fish and the extrapolated length of one-year-old fish for both sexes as shown below:

Female: $L_{n+1}=0.396 L_{n}+250.18(r=1)$

Male: $L_{n+1}=0.814 L_{n}+104.09(r=1)$

From Walford's growth transformation of older and younger mullet, the inflection points for both sexes were
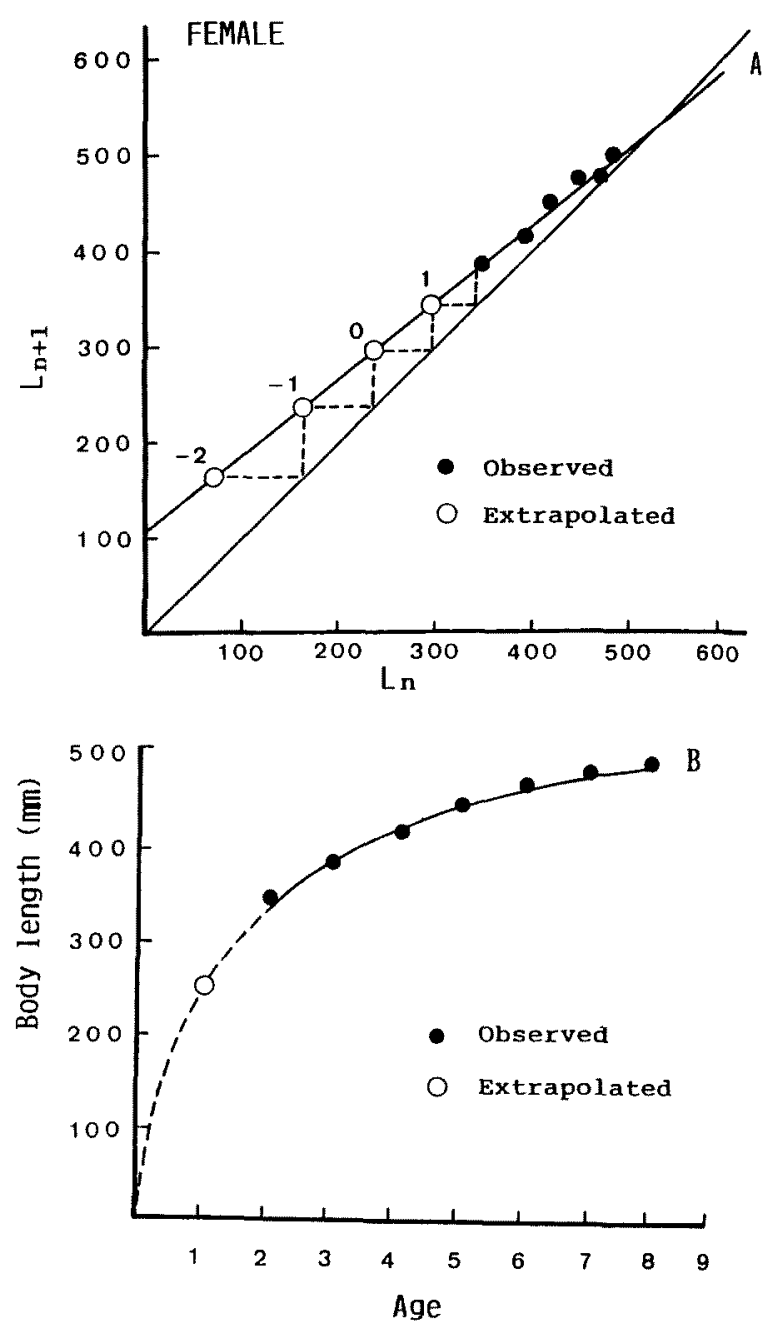

Fig. 1. Extrapolation of the age-length relationship depending both on Walford's plots (A) and on age-length curve adjusted freehand (B) in female grey mullet collected off the west coast of Taiwan.

obtaine as shown in Fig. 3. The length at the inflection points was calculated as $349 \mathrm{~mm}$ for females and $338 \mathrm{~mm}$ for males. Moreover, the inflection points were calculated as 2 years old for females and 2.1 years old for males when culculated based on the scales.

Von Bertalanffy's growth equations for both sexes are as follows:

Female

Less than 2 years old

$L_{n}=414[1-\exp (-0.926(n-0.021))]$

More than 2 years old

$L_{n}=560[1-\exp (-0.206(n+2.687))]$

Male

Less than 2.1 years old

$\mathrm{L}_{\mathrm{n}}=409[1-\exp (-0.835(\mathrm{n}+0.018))]$

More than 2.1 years old

$L_{n}=535[1-\exp (-0.227(n+2.303))]$

The female attains a larger size than the male every year (Fig. 4). 

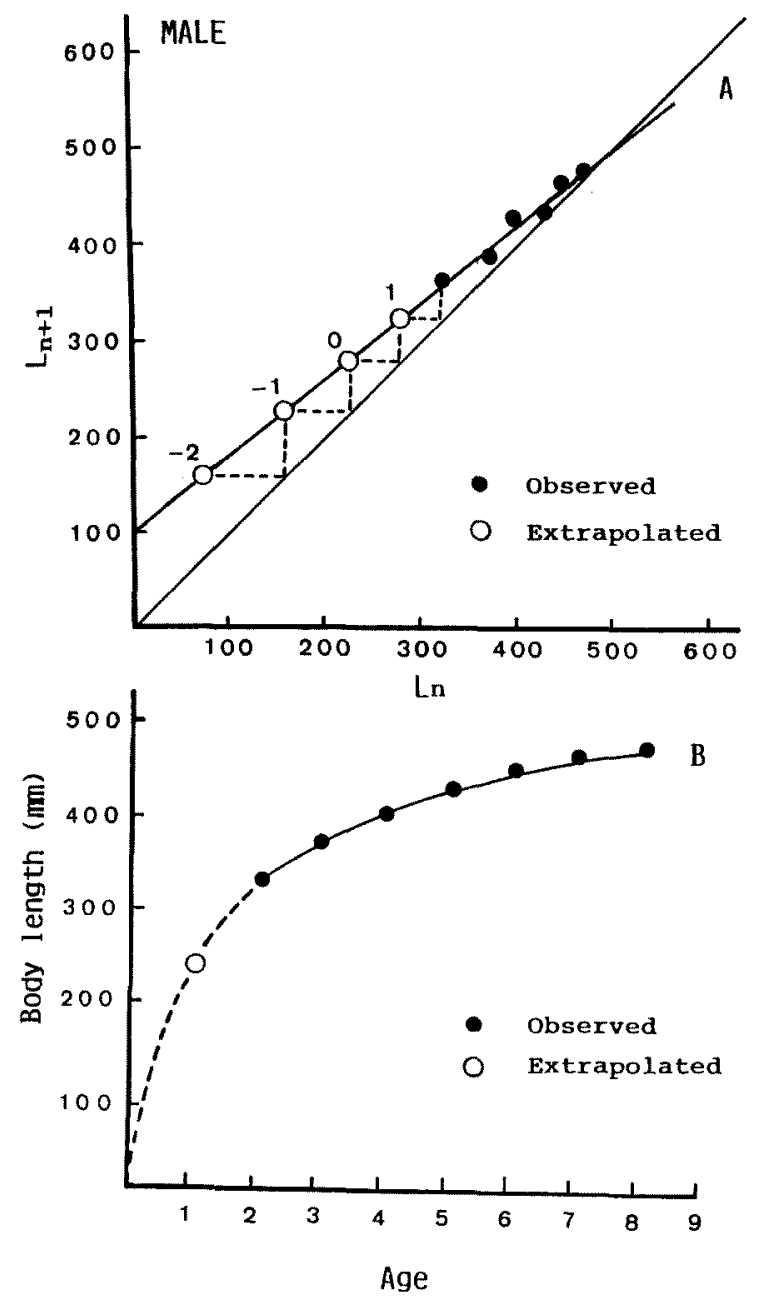

Fig. 2. Extrapolation of the age-length relationship depending both on Walford's plots (A) and on age-length curve adjusted freehand (B) in male grey mullet collected off the west coast of Taiwan.

\section{Reproduction}

Seasonal changes in gonosomatic index $(100 \times$ gonad weight/body weight), GSI, during the spawning season from November through January are shown for both sexes in Fig. 5. While the average GSI for females rose after early November and peaked at a high level of about $18 \%$ in early January the following year, that for males did not reach such a high level and almost leveled off after late November at $10-12 \%$.

Fecundity of the mullet, F, was regressed to ovary weight in grams, OW as follows:

$$
\mathrm{F}=(6.34 \mathrm{OW}+44.51) \times 10^{3}(\mathrm{r}=0.998)
$$

Regression of fecundity on body length was calculated as shown below (Fig. 6):

$$
\mathrm{F}=2.22 \times 10^{-4} \mathrm{BL}^{3.74}(\mathrm{r}=0.86)
$$

Frequency distributions of oocyte diameter are shown in Fig. 7 for fish with increasing GSIs. The distribution patterns are almost the same with peaks at $0.70 \mathrm{~mm}$ when the GSI is lower than 16.1 , and with peaks at $0.75 \mathrm{~mm}$ when the GSI is higher than 18.9.

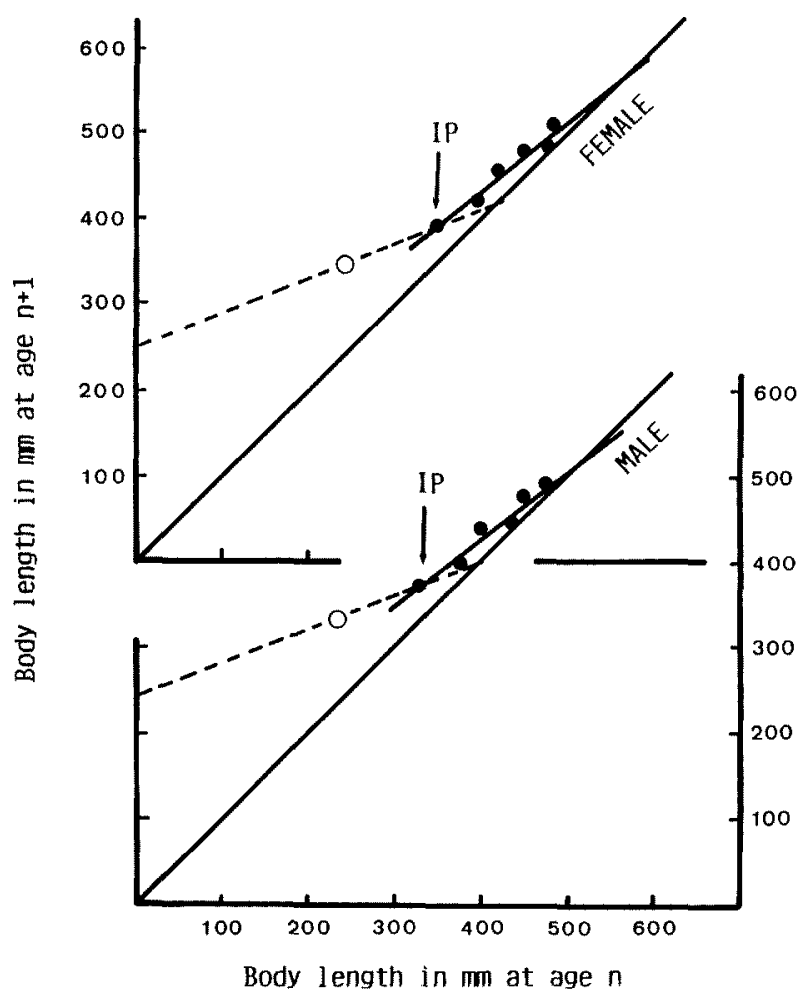

Fig. 3. Walford's plots for female and male grey mullet off Taiwan. Body length at 1 year was estimated by extrapolating the agelength curve based on the original data. IP: Inflection point of growth pattern.

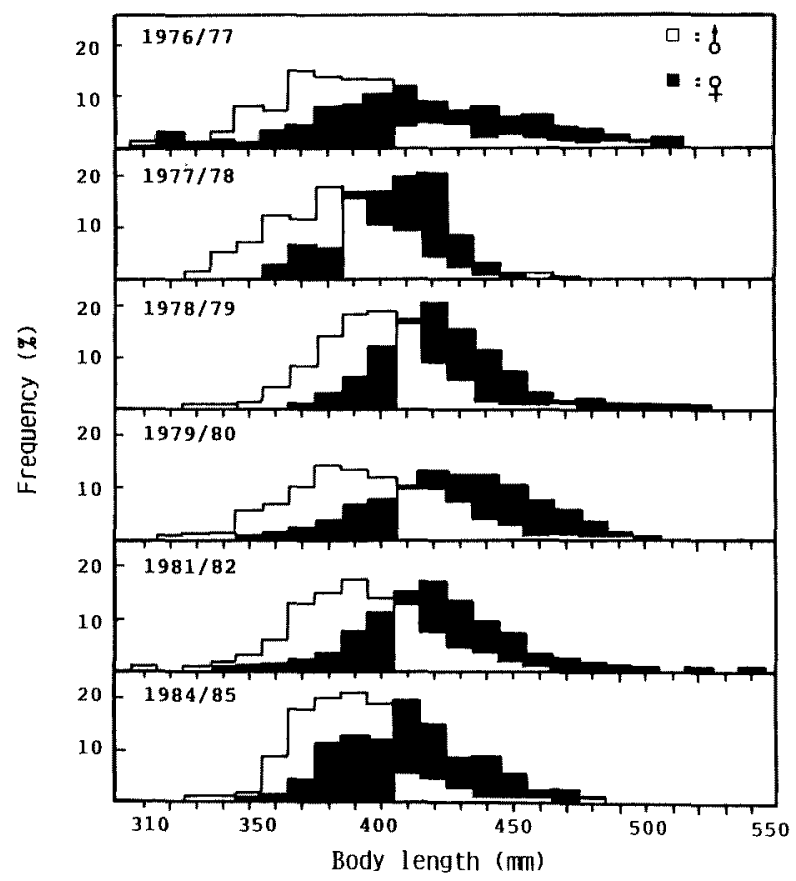

Fig. 4. Frequency occurrence of male and female grey mullet off Taiwan. 


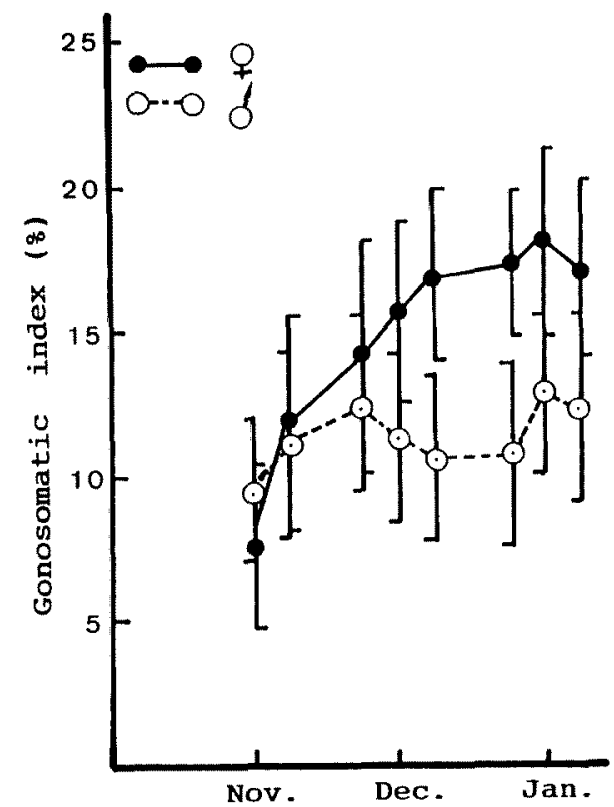

Fig. 5. Seasonal change in GSI of adult grey mullet by sex.

Points and vertical bars denote means and their standard deviation.

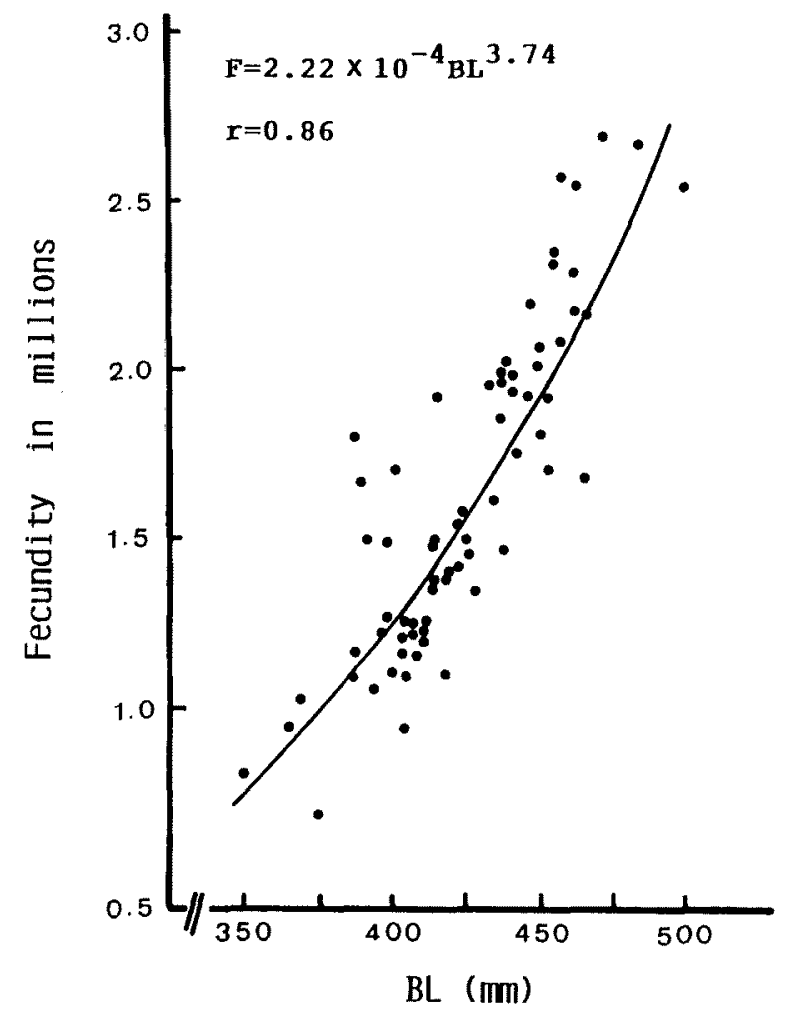

Fig. 6. Regression of fecundity (F) on body length (BL).

\section{Discussion}

As mentioned above, Lee's phenomenon is clearly observed for the grey mullet collected from the west of Tai-

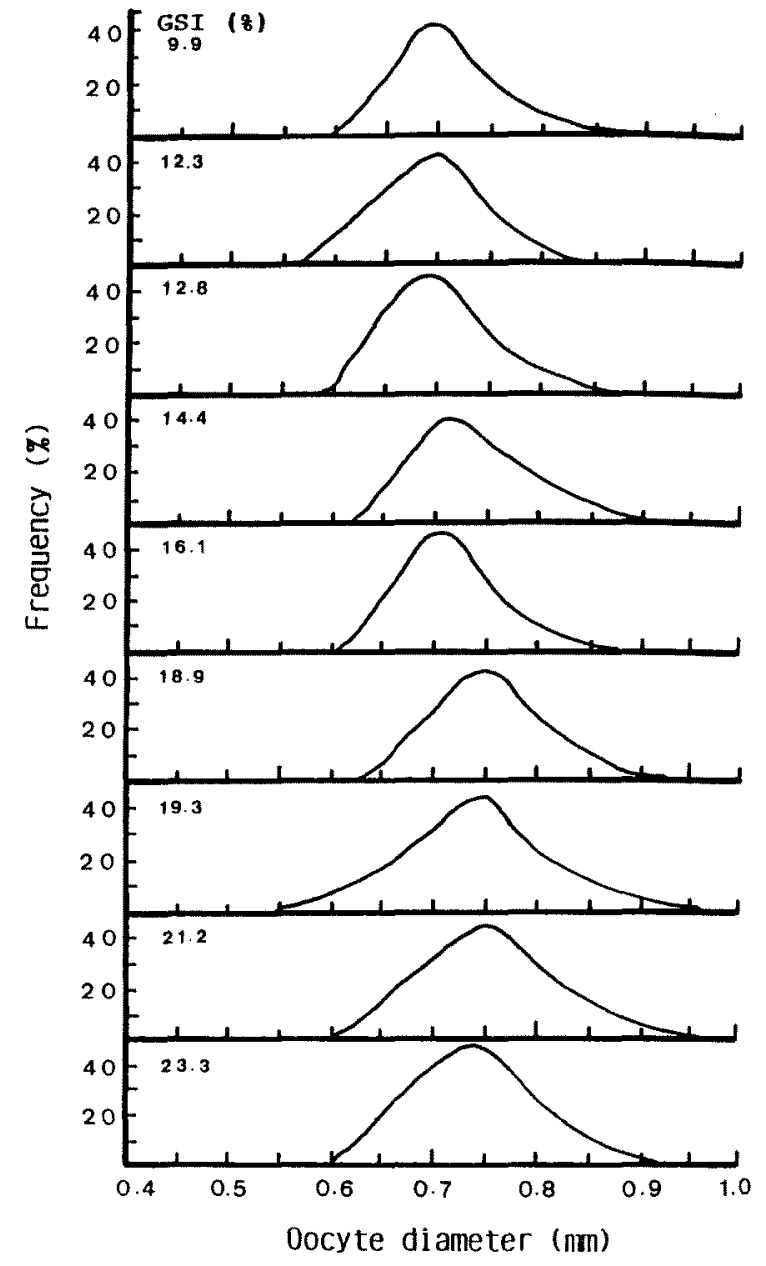

Fig. 7. Frequency occurrence of mature eggs with increasing GSIs.

wan, as noted already by Tung. ${ }^{1)}$ The phenomenon, however, has not been reported for this species for other areas in the world. ${ }^{11)}$

As shown in Table 2 and Fig. 4, the female grows larger than the male, indicating that on the whole more energy is allocated to the female than to the male. Such sexual dimorphism is a feature of the grey mullet's life history.11) Another feature of the mullet is its long life-span. From the annual age composition of grey mullet in Taiwan, ${ }^{4,12-15)}$ the life of the mullet is estimated to be 8 years.

The mullet shows an inflection of growth pattern at about 2 years. According to ths food habits of grey mullet, ${ }^{2)}$ this inflection is caused by the change of life pattern from pelagic to demersal life. ${ }^{2)} \mathrm{A}$ similar change of life pattern has been observed for the Pacific Ocean perch, Sebastes alutus. ${ }^{16)}$

As seen in Fig. 7, oocytes of highly matured mullet are small with peaks at $0.66-0.81 \mathrm{~mm}$. As Kawasaki previously pointed out, 7,8$)$ the egg size of most of the marine teleosts ranges from $0.6-1.6 \mathrm{~mm}$ in diameter, and smaller eggs tend to be buoyant compared to nonbuoyant larger eggs. Eggs of the mullet, however, are nonbuoyant in spite of their small size. The fecundity of the mullet is very high 


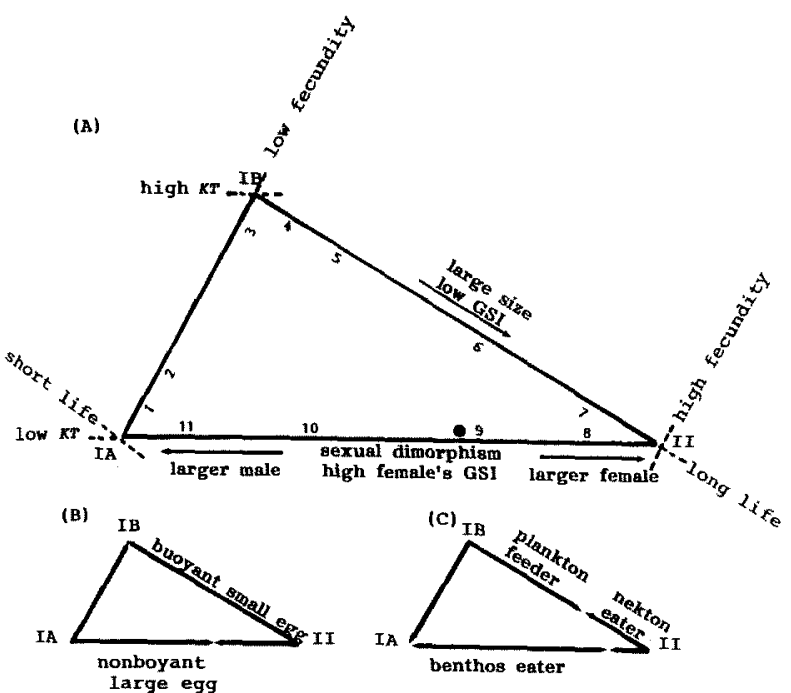

Fig. 8. Life history triangle of the teleosts in terns of three dimensions (A), nature of eggs (B) and food habit (C).

Numbers inside the figure (A) denote loci of each taxon shown below. For (A), $K$ is Bertalanffy's growth parameters and $T$ is the generation time.

1: saury, 2: sandeel, 3: herring, 4: sardine, 5: jack mackerel, 6 : chub mackerel, 7: tunas, 8: heterosomes, 9: gadoids, 10: gobies, 11 : snailfish, $\bullet$ : mullet.

Source: Kawasaki ${ }^{7,8)}$ and Kawasaki et al. ${ }^{97}$

at 0.5-3.0 millions (Fig. 6). This shows that the mullet lays a great number of small, nonbuoyant eggs.

Kawasaki ${ }^{7}{ }^{8)}$ and Kawasaki $e$ t al. ${ }^{\text {9) }}$ described three basic and extreme types for the pattern of fluctuating abundance of marine teleosts, which they named Subtype IA, Subtype IB and Type II. The abundance of each fish species fluctuates in accordance with one of these three patterns in an attempt to regulate its interaction with the environment.

Three types of life history triangle ${ }^{7-9)}$ are shown in Fig. 8. The triangle is made up of the lifespan, fecundity and growth rate. Type I species tend to have large-scale variations in abundance, whereas Type II fish populations remain stable. The Type II species are large-sized, longlived and slow-maturing, resulting in low $r$, which is the intrinsic rate of natural increase, compared to those of Type I species. The grey mullet is long-lived and lays a great number of nonbuoyant small eggs. The female grows larger and Lee's phenomenon is seen more clearly than in the male. The GSI attains a higher level for the female. The fish eats benthic organisms with bottom sand.2) Its pattern of fluctuation in biomass is fairly stable.

Based on all the life characteristics of the mullet, we can position it at a point closer to Apex II along Side IA-II as indicated in Fig. 8A.
The grey mullet from Taiwanese waters shows a life pattern different from the teleost fish that have been examined to date from an evolutionary ecological viewpoint, and its positioning in the life history triangle is of scientific value.

Acknowledgments We thank Messrs. W. Y. Chen and C. S. Huang and other staff of the Kaohsiung Branch, Taiwan Fisheries Research Institute, for their assistance in the survey and sample collection.

\section{References}

1) I. H. Tung: Age determination of the grey mullet. China Fish. Month., 80, 2-10 (1959) (in Chinese).

2) I. H. Tung: On the fishery biology of the grey mullet Mugil cephalus in Taiwan. Report of the Institute of Fishery Biology of Ministry of Economic Affairs and National Taiwan University, 3, 38-101 (1981) (in Chinese).

3) W. Y. Chen and W. C. Su: Reproductive biology of the grey mullet, Mugil cphalus L. of Taiwan. Special report of study on the resources of grey mullet in Taiwan, 1983-1985, Kaohsiung Branch, TFRI, Kaohsing, 1986, pp. 73-80 (in Chinese).

4) C. S. Huang and W. C. Su: Studies on the fluctuations of fishing conditions for grey mullet (Mugil cephalus Linnaeus) from the western coast of Taiwan. J. Fish. Soc., Taiwan, 16, 47-83 (1989) (in Chinese).

5) W. Y. Chen, W. C. Su, K. T. Shao, and C. P. Lin: Morphometric studies of the grey mullet (Mugil cephalus) from the waters around Taiwan. J. Fish. Soc., Taiwan, 16, 153-164 (1989).

6) S. Y. Huang, C. L. Kuo, and S. Tanaka: Stock assessment of grey mullet Mugil cephalus in Taiwan by cohort analysis. Nippon Suisan Gakkaishi, 56, 1955-1963 (1990).

7) T. Kawasaki: Fundamental relations among the selections of life history in the marine teleosts. Nippon Suisan Gakkaishi, 46, 289293 (1980).

8) T. Kawasaki: Pelagic Fish Resources, Koseisha-Koseikaku Press, Tokyo, 1982, p. 157 (in Japanese).

9) T. Kawasaki, H. Hashimoto, H. Honda, and A. Otake: Selection of life histories and its adaptive significance in a snailfish Liparis tanakai from Sendai Bay. Nippon Suisan Gakkaishi, 49, 367-377 (1983).

10) A. Shinjou: An Introduction to Biostatistics, Asakura-Shoten Press, Tokyo, 1986, pp. 46-63.

11) J. P. Quignard and H. Farrugio: Age and growth of grey mullet, in "Aquaculture of Grey Mullet" (ed. by O. H. Oren), Cambridge University Press, London, 1981, pp. 155-184.

12) J. S. Lin: Investigation on the migration of grey mullet in 1976. Bull. Taiwan Fish. Res. Ins., 29, 141-177 (1977) (in Chinese).

13) J. S. Lin: An investigation on grey mullet (Mugil cephalus Linnaeus) resource in Taiwan, 1978-1979. Bull. Taiwan Fish. Res. Ins., 31, 283-298 (1979) (in Chinese).

14) J. S. Lin: An investigation on grey mullet (Mugil cephalus Linnaeus) resource in Taiwan, 1979-1980. Bull. Taiwan Fish. Res. Ins., 32, 235-254 (1980) (in Chinese).

15) S. Y. Hwang: Age composition, size distribution and length-weight relationship of grey mullet (Mugil cephalus) in 1984. Special report of study on the resources of grey mullet in Taiwan, 1983-1985. Kaohsiung Branch, TFRI, Kaohsiung, 1986, pp. 57-61 (in Chinese).

16) S. Chikuni: Biological study on the population of the Pacific Ocean perch in the North Pacific. Bull. far Seas Fish. Res. Lab., 12, 1-102 (1975) (in Japanese). 